\title{
Self-assembly of hypervalent iodine through primary and secondary bonding
}

\author{
Paul Kiprof* and Viktor Zhdankin \\ Department of Chemistry, University of Minnesota Duluth, 1039 University Avenue, Duluth, MN \\ 55812, USA \\ E-mail:pkiprof@d.umn.edu
}

\section{Dedicated to Professor Anastasios Varvoglis on the occasion of his $65^{\text {th }}$ birthday}

(received 01 Feb 03; accepted 03 June 03; published on the web 09 June 03)

\begin{abstract}
The self-assembly of two hypervalent iodine compounds to trimers was studied using molecular orbital calculations. The driving force for the self-assembly is the formation of secondary bonding interactions between molecules and in the second case a rearrangement of primary and secondary bonding around iodine to place the least electronegative substitutent in the equatorial position for every iodine in the trimer.
\end{abstract}

Keywords: Hypervalent, iodine, self-assembly, ab initio, density functional, primary bonding, secondary bonding

\section{Introduction}

Hypervalent iodine compounds have many applications in organic synthesis. They either enable organic transformations to be performed more selectively or facilitate conversions impossible with other reagents. $^{1}$

Molecular self-assembly is a widely studied phenomenon, but has been mostly focused on coordination chemistry and hydrogen bonding. Only little is known in the field of self-assembly of hypervalent compounds. ${ }^{2}$

The goal of this paper is to analyze driving forces in the formation of self-assemblies of hypervalent iodine compounds, benziodoxole and benziodazoles derivatives. The bonding in hypervalent compounds has been addressed in general and also in special cases. ${ }^{3}$ Hypervalent iodine 10-I-5 typically adopts a T-shaped geometry derived from a trigonal bipyramidal electron pair geometry, with the least electronegative substituent preferring an equatorial position, i.e. the base of the "T" and the two more electronegative substituents in the axial positions, trans to each other. Hypervalent iodine compounds can form polymeric structures through establishment of 
secondary bonds, as seen in iodosylbenzene and related compounds. ${ }^{4}$ Secondary bonding can be compared to dative bonds in Lewis Acid-Base chemistry.

\section{Results and Discussion}

We investigated, using theoretical methods, the formation of two cyclic, trimeric self-assemblies of hypervalent iodine compounds as in the case of $\mathbf{1}$, reported by Ochiai and coworkers (Scheme 1 ), ${ }^{5}$ and 2 , respectively (Scheme 2$){ }^{6}$

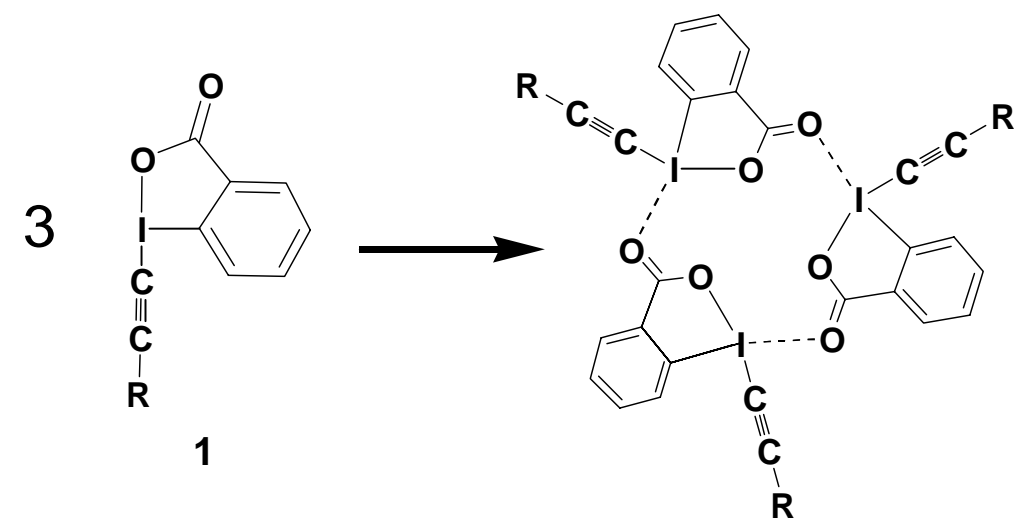

\section{Scheme 1}

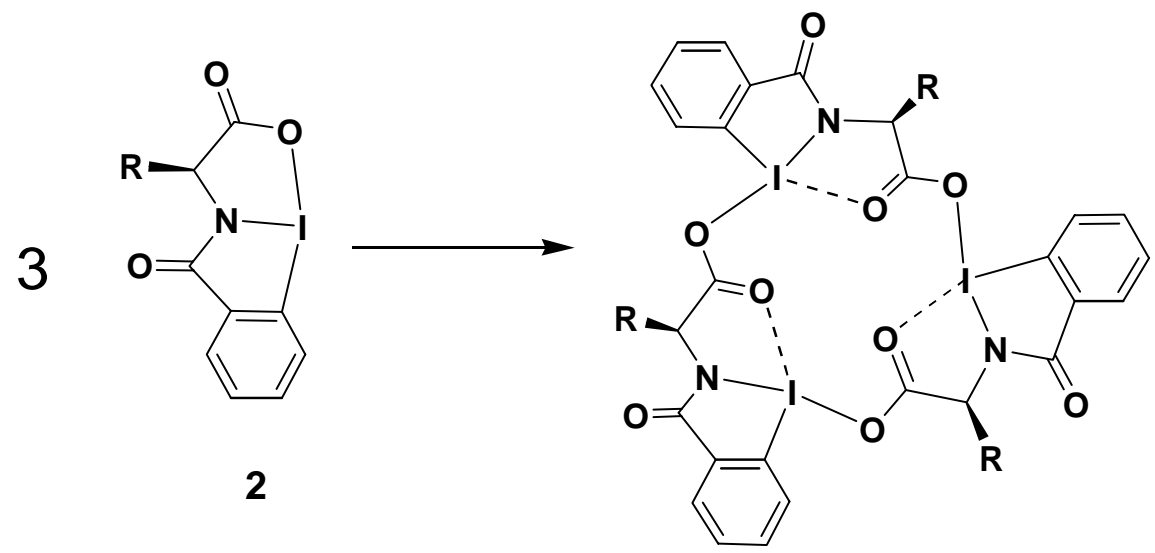

\section{Scheme 2}

To the best of our knowledge, self-assembly is not observed for the parent of this class of compounds, benziodoxole. Only weak secondary intermolecular interactions exist between molecules in the crystal. ${ }^{7}$

Compared with 1-acetoxy-benziodoxole $(2.13 \AA)^{7 b}$, the endocyclic I-O bond of $\mathbf{1}$ is considerably longer (2.29 Å) (Figure 1). 


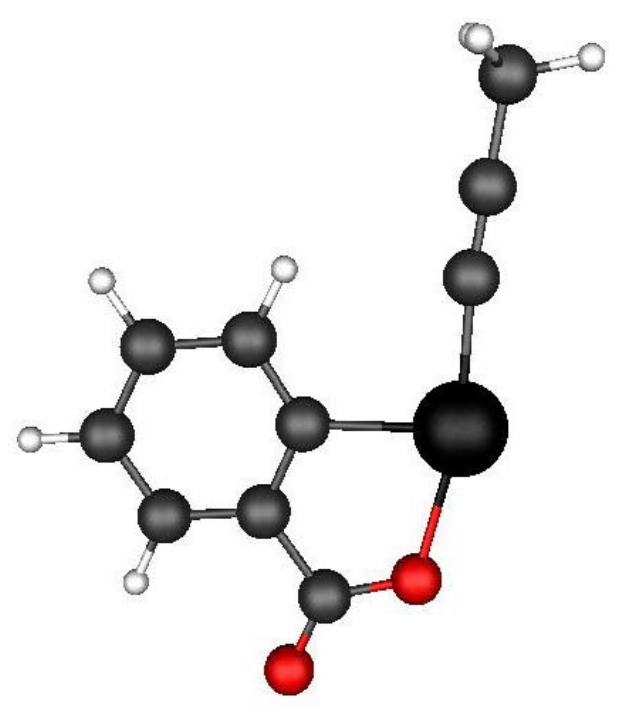

Figure 1. Calculated Structure of $\mathbf{1}$ without self-assembly.

This was interpreted by the authors as a more ionic iodine oxygen bond. A review of crystal structures containing a $\mathrm{PhIO}_{2}$ fragment in a T-shape geometry showed a good correlation between the two iodine oxygen bond lengths. ${ }^{8}$ The shorter (more covalent) one distance is, i.e. the longer (more ionic) the other becomes. In the case of $\mathbf{1}$ the iodine carbon bond is more covalent and the trans iodine oxygen bond has more ionic character and is therefore longer. This lengthening of the I-O bond gives rise to another substituent entering the coordination sphere of iodine and a trimerization of the molecule in the solid state. The carbonyl oxygen of another molecule of $\mathbf{1}$ establishes a purely secondary bond.

The energy gain for this interaction is $34.3 \mathrm{kcal} / \mathrm{mol}$ (average energy gain of each monomer is $11.4 \mathrm{kcal} / \mathrm{mol}$ ). The establishment of a secondary, intermolecular bond weakens the endocyclic I-O bond as its length increases to $2.42 \AA$ in the calculations. The determination of the intermolecular I-O distances is with 2.77 and $3.29 \AA$ very close to the experimental values (Figure 2). The slight overestimation of the endocyclic I-O distance and underestimation of the second, longer intermolecular I-O distance are connected and could be related to interaction of water of crystallization in the crystal lattice of $\mathbf{1}$ with the trimer. 


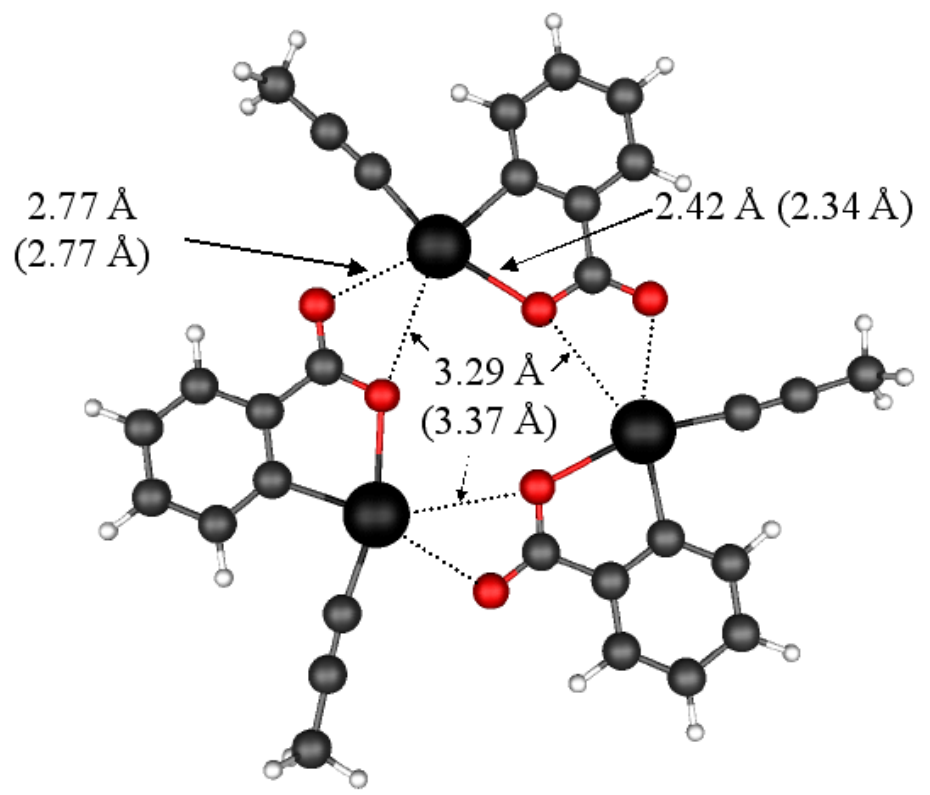

Figure 2. The trimer of 1. Calculated and observed (in parentheses) I-O distances are indicated.

The structure of the monomers remains essentially intact. The self-assembly is strictly through secondary bonding to the carbonyl oxygen and, to a lesser extent, to the endocyclic oxygen. As a result, the total coordination number of iodine is five.

By way of contrast, the self-assembly (trimerization) of 2 leads to a rearrangement of the primary and secondary bonding (Scheme 2).

The monomer of $\mathbf{2}$ is an example of the recently established class of benziodazoles. ${ }^{9}$ However, because of the bicyclic nature of $\mathbf{2}$, the least electronegative substituent is forced into an axial position and an electronegative substituent into an equatorial position, resulting in a trans configuration of an electronegative substituents $(\mathrm{O})$ and a less electronegative substituents (C), which favors a more covalent bond (Scheme 3). This unstable arrangement of substituents is alleviated by intermolecular self-assembly of 2 .<smiles>[R]C1C(=O)OI2C(=O)c3ccccc3N12</smiles>

2<smiles>CC(=O)OI1NC(=O)c2ccccc21</smiles>

3

\section{Scheme 3}

Different isomers and conformers of 3 that have a trans O-I-N or trans O-I-C arrangement were investigated (Scheme 4). 


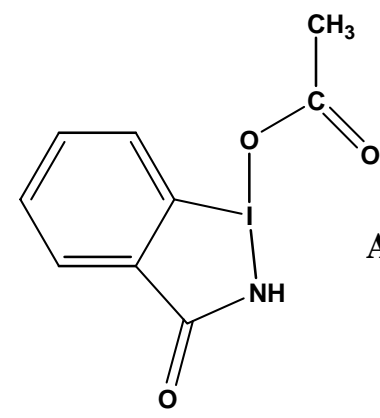

A: $0.0 \mathrm{kcal} / \mathrm{mol}$

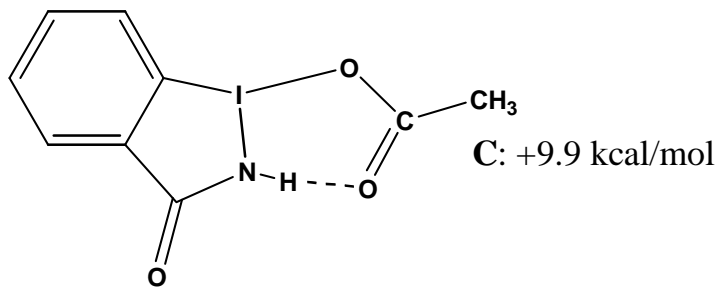

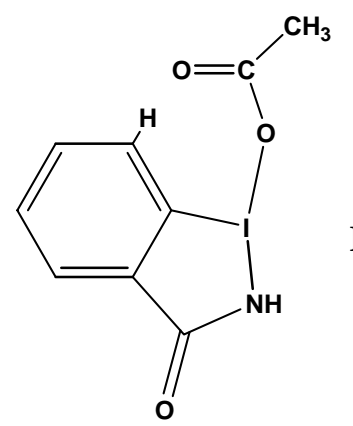

B: $+4.6 \mathrm{kcal} / \mathrm{mol}$ (transition state)

Scheme 4. Calculated Isomers and Conformers of Benziodazole 3 and relative energies.

All isomers with the trans O-I-C arrangement (C and $\mathbf{D})$ have higher relative energies than the ones with trans O-I-N (A and B) arrangements. The lowest energy structure is consistent with the one observed in the solid state. ${ }^{9}$ Both trans O-I-C structures are either 9.9 or 12.3 $\mathrm{kcal} / \mathrm{mol}$ higher in energy than the lowest energy structure. One of the structures, $\mathbf{C}$, exhibits an intramolecular hydrogen bond which contributes to its stabilization. It is therefore ca. 2.4 $\mathrm{kcal} / \mathrm{mol}$ lower in energy than its conformer $\mathbf{D}$ (Figures 4 and 5). The clear preference in benziodazoles is to have the electronegative substituents in a trans arrangement.

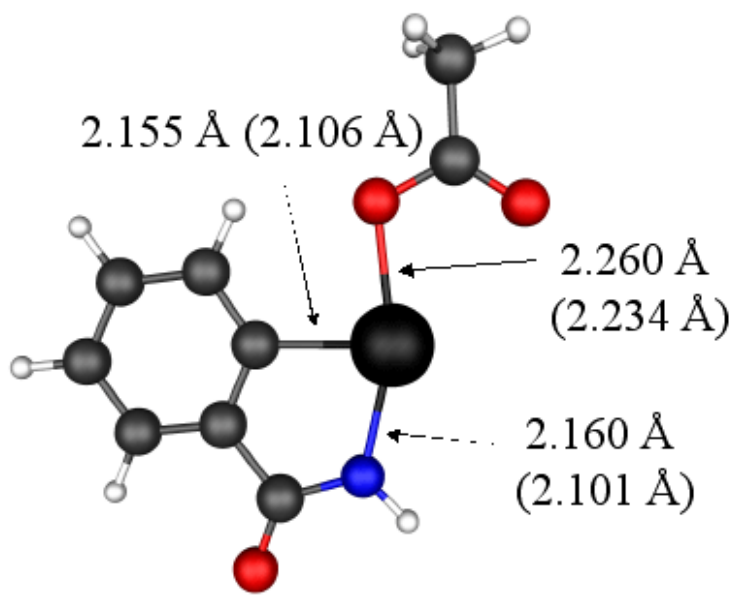

Figure 4. Calculated geometry of benziodazole 3 (A) with calculated distances. Experimental distances are in parentheses. The angle N-I-O was calculated as $161.3^{\circ}\left(162.1^{\circ}\right.$ were observed). 

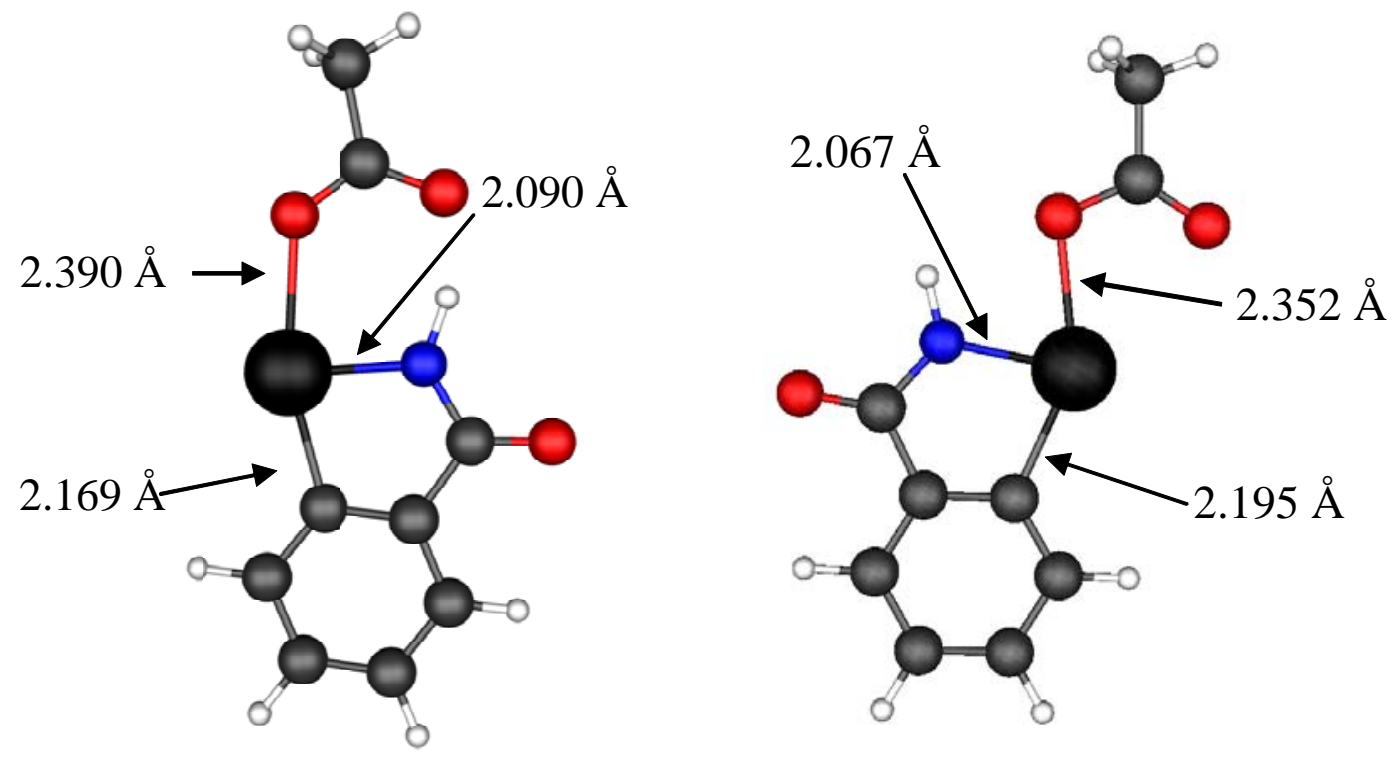

Figure 5. Calculated Structures of conformers $\mathbf{C}$ and $\mathbf{D}$.

In 2, through the attachment of the nitrogen containing substituent to the carboxylate, the unfavorable isomer is forced upon the structure (Figure 6). This leads to the formation of a new intermolecular bond between monomers of 2 .

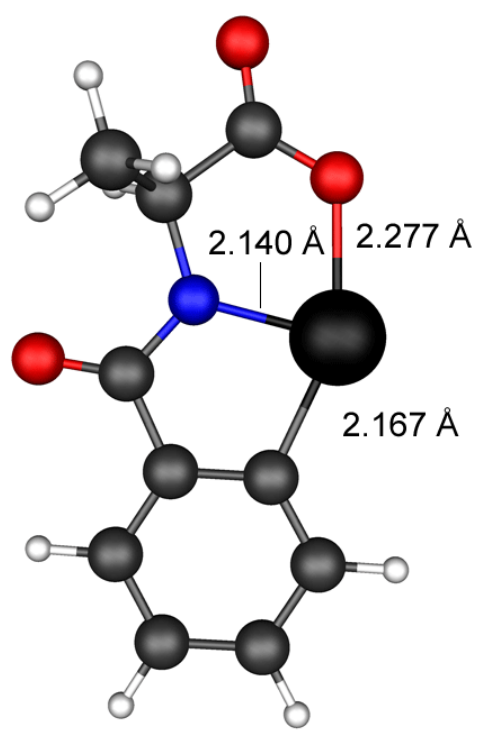

Figure 6. Calculated Structure of the monomer of 2.

However, because of the bicyclic nature of the molecule, the increase in the I-O distance is not as significant as in the unrestricted structures. It is close to the one seen for $\mathbf{3}$. 
The intermolecular bond formation restores the preferred placement of the two most electronegative substituents in the axial positions and the aromatic ring in the equatorial. Thus, the intermolecular bond becomes a primary bond (part of the T-shaped arrangement of substituents), while the intramolecular I-O bond now only serves as a secondary bond (Figure 7).

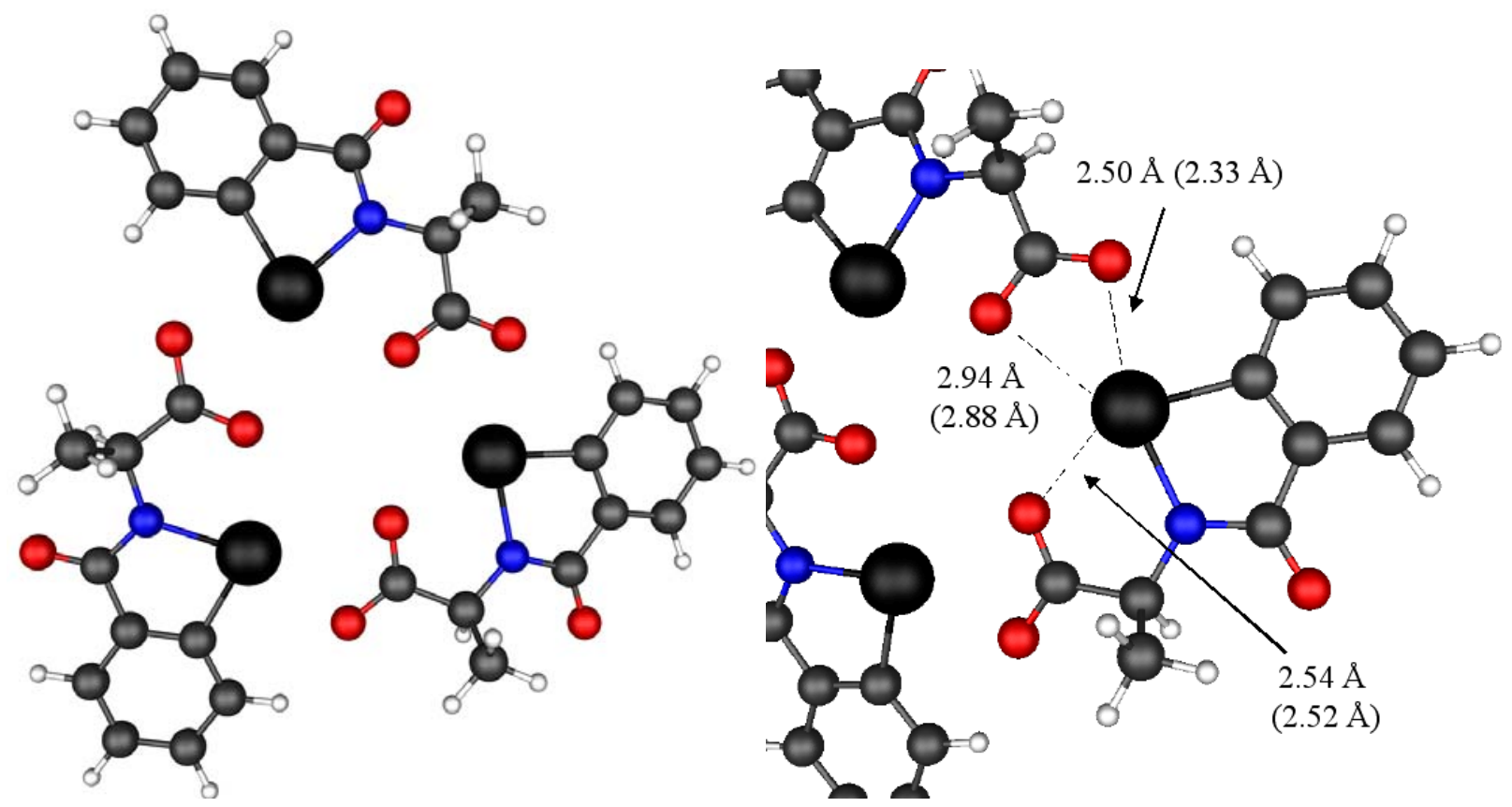

Figure 7. Calculated Structure of the trimer of $\mathbf{2}$ with a detail of the trimer structure with important calculated distances and observed distances in parentheses.

The energy released related to the formation of the trimer is $77.1 \mathrm{kcal} / \mathrm{mol}(25.7 \mathrm{kcal} / \mathrm{mol}$ per monomer). This value is considerably higher than for $\mathbf{1}$. The trimerization leaves a gap behind in the center of the molecule, which is the location of a chloroform molecule in the solid-state structure (Figure 7). ${ }^{6}$

The intermolecular I-O distance is overestimated. This may be due to the fact that a chloroform solvent molecule is in the gap of the structure in the crystal. All other important features agree well with the experimental data.

\section{Experimental Section}

General Procedures. All calculations were done at the HF/LANL2DZ and B3LYP/LANL2DZ levels of theory using the programs Gaussian $94^{10}$ and Gaussian $98^{11}$ on a Silicon Graphics Origin 3000 Cluster, Sunblade 1000 and 2000 workstations and a Silicon Graphics Octane workstation. Molecular images were created using MacMolPlt ${ }^{12}$. 


\section{Acknowledgement}

We would like to thank the Supercomputing Institute for Digital Simulation and Advanced Computation of the University of Minnesota and the Visualization and Digital Imaging Laboratory at the University of Minnesota Duluth for valuable computer resources.

\section{References}

1. (a) Varvoglis, A. Hypervalent Iodine in Organic Synthesis; Academic Press: London 1997.

(b) Stang, P. J.; Zhdankin, V. V. Chem. Rev. 1996, 96, 1123. (c) Zhdankin, V. V.; Stang, P. J. Chem. Rev. 2002, 102, 2523.

2. Comprehensive Supramolecular Chemistry; Lehn, J.-M., Chair Ed.; Atwood, J. L., Davis, J. E. D., MacNicol, D. D., Vögtle, F., Exec. Eds; Pergamon: Oxford, UK, 1987-1996; Vols. 111. (b) Leininger, S.; Olenyuk, B.; Stang, P. J. Chem. Rev. 2000, 100, 853.

3. (a) Reed, A. E.; Schleyer, P. v. R. J. Am. Chem. Soc. 1990, 112, 1434. (b) Zhdankin, V. V.; Arbit, R. M.; Lynch, B. J; Kiprof, P. Young, V. G. J. Org. Chem. 1998, 63, 6590.

4. (a) Macikenas, D.; Skrzypczak-Jankun, E.; Protasiewicz, J. D. Angew. Chem., Int. Ed. 2000, 39, 2007. (b) Boucher, M.; Macikenas, D.; Ren. T.; Protasiewicz, J. D. J. Am. Chem. Soc. 1999, 121, 7164. (c) Batchelor, R. J.; Birchall, T.; Sawyer, J. F. Inorg. Chem. 1986, 25, 1415. (d) Boucher, M.; Macikenas, D.; Ren, T.; Protasiewicz, J. D. J. Am. Chem. Soc. 1997, 119, 9366.

5. M. Ochiai, M.; Masaki, Y.; Shiro, M. J. Org. Chem. 1991, 56, 551.

6. Zhdankin, V. V.; Koposov, A. E.; Smart, J. T.; Tykwinski, R. R; McDonald, R; MoralesIzquierdo, A. J. Amer. Chem. Soc. 2001, 123, 4095.

7. See for example: (a) Shefter, E.; Wolf, W. J. Pharm. Sci. 1965, 54, 104. (b) Gougoutas, J. Z.; Clardy, J. C. J. Solid State Chem. 1972, 4, 226.

8. Kiprof, P. unpublished results.

9. Zhdankin, V. V.; Arbit, R. M.; McSherry, M.; Mismash, B.; Young, V. G. J. Am. Chem. Soc. 1997, 119, 7408.

10. Gaussian 94, Revision E.2, Frisch, M. J.; Trucks, G. W.; Schlegel, H. B.; Johnson, B.; Robb, M. A.; Cheeseman, J. R.; Keith, T.; Petersson, G.A.; Montgomery, J. A. Jr.; Raghavachari, K.; Al-Laham, M. A.; Zakrzewski, V. G.; Ortiz, J. V.; Foresman, J. B.; Cioslowski, J.; Stefanov, B. B.; Nanayakkara, A.; Challacombe, M.; Peng, C. Y.; Ayala, P. Y.; Chen, W.; Wong, M. W.; Andres, J. L.; Replogle, E. S.; Gomperts, R.; Martin, R. L.; Fox, D. J.; HeadGordon, M.; Gonzalez, C.; Pople, J.A., Gaussian, Inc., Pittsburgh, PA, 1995.

11. Gaussian 98, Revision A.11, Frisch, M.J.; Trucks, G.W.; Schlegel, H.B.; Scuseria, G.E.; Robb, M.A.; Cheeseman, J.R.; Zakrzewski, V.G.; Montgomery Jr., J.A.; Stratmann, R.E.; Burant, J.C.; Dapprich, S.; Millam, J.M.; Daniels, A.D.; Kudin, K.N.; Strain, M.C.; Farkas, O.; Tomasi, J.; Barone, V.; Cossi, M.; Cammi, R.; Mennucci, B.; Pomelli, C.; Adamo, C.; 
Clifford, S.; Ochterski, J.; Petersson, G.A.; Ayala, P.Y.; Cui, Q.; Morokuma, K.; Salvador, P.; Dannenberg, J.J.; Malick, D.K.; Rabuck, A.D.; Raghavachari, K.; Foresman, J.B.; Cioslowski, J.; Ortiz, J.V.; Baboul, A.G.; Stefanov, B.B.; Liu, G.; Liashenko, A.; Piskorz, P.; Komaromi, I.; Gomperts, R.; Martin, R.L.; Fox, D.J.; Keith, T.; Al-Laham, M.A.; Peng, C.Y.; Nanayakkara, A.; Challacombe, M.; Gill, P.M.W.; Johnson, B.; Chen, W.; Wong, M.W.; Andres, J.L.; Gonzalez, C.; Head-Gordon, M.; Replogle, E.S.; Pople, J.A. Gaussian, Inc., Pittsburgh, PA, 2001.

12. Bode, B. M.; Gordon, M. S. J. Mol. Graphics 1999, 16, 133. 